\title{
A INFLUÊNCIA dO SLOGAN NA PERCEPÇÃO DOS VALORES DA MARCA PELOS CONSUMIDORES
}

Mariangela Barbosa Fazano Amendola, Olavo Martins Junior, Camila Antunes Begini, Maria Lígia de Oliveira Gomes Martins

Universidade do Oeste Paulista - UNOESTE, Curso de Comunicação Social, Presidente Prudente, SP.E-mail: olavomj@hotmail.com.

\section{RESUMO}

O presente artigo tem como objetivo mostrar como é possível uma marca mostrar seu posicionamento ao seu público-alvo por meio de seus slogans. Para entender essa relação e como ela é feita, será realizada pesquisa documental e bibliográfica e posterior análise de slogans e princípios da marca Coca-Cola. A partir desta análise pretende-se entender essa relação e como ela se estabelece e quais recursos linguísticos a marca utiliza para persuadir o seu consumidor.

Palavras-chave: slogan, publicidade, posicionamento, marcas

\section{THE SLOGAN INFLUENCE IN THE BRANDS PERCEPTION BY THE CONSUMERS}

\begin{abstract}
The presente article has as objective reflect how is possible that a brand can reveal their positioning to the target by their slogans. To undestand this connexion and how it works, will be doing a bibliografic and documentar research and further analysis of slogans and Coca-Cola brand principles. From this analysis will be intends the connexion and how it Works and what king of linguistic resource the brands use to persuade their consumers.
\end{abstract}

Keyword: slogan, advertisiment, positioning, brand 


\section{INTRODUÇÃO}

O presente artigo como finalidade estudar a relação que existe entre os slogans e os valores que a empresa quer passar e como esses são criados, quais figuras de linguagem são utilizadas e como se estabelece essas relações de forma simples e que seja fácil de absorver pelos consumidores.

\section{POSICIONAMENTO}

Um dos grandes desafios de uma marca ou empresa é conseguir um bom posicionamento na mente dos seus clientes e consumidores.

Na visão de Ries e Trout (1993 p. 2), "o posicionamento começa com o produto. Uma peça de "merchandising", um serviço, uma empresa, uma instituição, ou mesmo uma pessoa. Talvez você mesmo ". Sendo assim o posicionamento não é algo exclusivamente de um produto ou marca, uma mesma marca com diversas linhas de produtos pode ter um posicionamento para cada um deles e um para ela.

Para Kotler e Armstrong (2007), o posicionamento de um produto é a maneira como o produto é visto pelos consumidores em relação aos seus atributos, é o lugar que ele ocupa na mente do consumidores em relação aos concorrentes.

Segundo Perez (2004), além do slogan, as marcas se comunicam através do logotipo, das formas e design, dos produtos, rótulos, cor, jingles, personagem que a representa, mascote, além de outros recursos e do contexto e do contexto organizacional, envolvendo funcionários e parceiros e sua relação com o meio social.

\section{SLOGAN}

Uma das armas utilizadas pelas empresas para fixar seu posicionamento é o slogan, que geralmente traduzem de forma sucinta e clara como a marca gostaria de ser vista.

Segundo lasbeck (2002 apud Reboul, 1986, p.) "O termo slogan tal como nos chegou, é de origem francesa. No entanto, ele remonta, segundo Oliver Reboul, à expressão escocesa "shuaghghairm", que quer dizer 'grito de guerra de um clã' ". Levado para o meio publicitário o slogan seria o grito de guerra das empresas e marcas na busca de fidelização cientes e consumidores.

Por muito tempo o termo slogan foi utilizado no meio político, até mesmo com sentido pejorativo, designando a divisão de um partido político, de uma ideologia ou de uma linha filosófica. Os Estados Unidos foi o responsável por tornar o termo francês conhecido em todo o mundo na acepção comercial, como é vista até hoje. (IASBECK, 2002)

Perez reforça ainda que "O sentido que hoje temos para slogan foi consagrado pelos Estados Unidos, que partiu do francesismo para torna-lo expressão de divisa comercial “.

Para Perez (2004), slogan:

[...] são frases ou sentenças concisas usadas repetidamente nas propagandas de uma empresa, produto ou serviço. O slogan é o comando que desperta associações funcionais e emocionais. Quando bem construído e representativo, ele oraliza máximas que a coletividade vive piamente como verdadeiras, tornando-se parte do cotidiano.

Segundo a definição de Negri (2011), nomeia-se slogan como a assinatura verbal de uma marca, ou de determinados produtos e serviços de destaque ou com forte presença mercadológica.

O slogan não é um título e nem deve ser confundido como tal numa peça publicitária, tanto em sua construção como em sua função. Títulos e textos estão ligados aos conceitos da campanha, enquanto os slogans devem funcionar como uma extensão verbal do espírito da marca. (NEGRI, 2011) 


\section{O LUGAR DO SLOGAN}

Dentro das campanhas publicitárias o slogan tem seu lugar de destaque, e não deve nunca ser confundido com os outros elementos do anúncio, como títulos ou textos.

Em anúncios impressos costuma vir destacado em tipos e calibres mais expressivo, ecimando a ilustração ou texto argumentativo, ou ambos. Pode aparecer também junto a assinatura, logomarca ou emblema do anunciante. Na publicidade dinâmica, TV ou cinema, o slogan geralmente aparece no início ou no fina da apresentação, com a finalidade de ser justificado ou consolidar um juízo expostos no filme publicitário. (IASBECK, 2002).

De acordo com Negri (2011), os slogans são inscritos no rodapé dos anúncios, outdoors, busdoors, etc., próximos ao logotipo das marcas que assinam, e alocados de forma visível, mas discreta, quase sempre em tipologia pequena, mas visível ao público.

A localização do slogan não é o melhor critério para identificar o mesmo. Ele se torna fácil de reconhecer por algumas peculiaridades de sua estrutura: frase concisa e marcante, geralmente incisiva, atraente, de fácil percepção e memorização, que apregoa as qualidades e a superioridade de um produto, serviço ou ideia. (IASBECK, 2002)

Um dos fatores que facilitam a memorização do slogan é a repetição, quanto mais o consumidor ouve ou lê, mais ele memoriza e o associa a marca. Muitas marcas como a Coca-Cola, que é nosso objeto de estudo, trabalham um mesmo slogan por muitos anos em diversas campanhas, mudando apenas quando a empresa deseja mudar seu posicionamento ou reformular o mesmo.

\section{FUNÇÕES DO SLOGAN}

De acordo com Perez (2004), o papel do slogan é de aproximar os consumidores das marcas e dos produtos que pretende promover. Sua função é colaborar para a fixação e conhecimento da marca.

Ainda segundo Bertomeu (2006, p. 57):

Um verdadeiro slogan não apenas prende a atenção, mas fecha a comunicação sobre si mesmo, excluindo qualquer interferência. O slogan tem sentido completo e não precisa de uma imagem ou de outra forma de texto para completar o seu sentido.

Negri (2011) ressalta que cabe ao slogan explicitar de modo engenhoso a inclinação ideológica de um marca anunciante e traduzi-la sob forma verbal. Assim como o logotipo faz na forma visual.

Para que um slogan funcione como slogan, não é preciso que venha acompanhado de ilustrações, texto maior que o explique ou assinatura do cliente. $O$ slogan deve funcionar como slogan de forma autônoma. (IASBECK, 2002)

\section{DO QUE SÃO FEITOS OS SLOGANS}

O fato é que os slogans têm por destinatários um púbico heterogêneo e geograficamente disperso, para os quais essas estruturas conseguem evitar o pensamento reflexivo sobre o que se afirma, mesmo com texto curto. Para haver comunicação imediata, não é recomendável que o texto permita ao leitor perder tempo em tentando buscar significados. $O$ fato de não possuir um autor declarado, faz com que o slogan tente construir identidade consigo mesmo, ao ponto de eliminar ao máximo a possibilidade de novas proliferações sígnicas auxiliares. (IASBECK, 2002)

Assim como os títulos e os textos publicitários, os slogans também são formados utilizando diversos recursos linguísticos para atingir seus objetivos comerciais.

lasbeck (2002), ressalta alguns desses recursos linguísticos utilizados na construção de slogans, como clichês e chavões, frases de arrastão, frases entrecortadas, frase de ladainha, frase 
labiríntica, frases fragmentárias e figuras de estilo. São inúmeros os recursos para a construções de bons slogans que fixe na mente do consumidor todos os atributos que a marca deseja passar.

Dentro eles, alguns destacam-se por serem usados com mais frequência, é o caso das figuras de linguagem metáfora e metonímia. Além de serem as mais usadas, metáfora e metonímia geram grande confusão na cabeça até mesmo dos publicitários, devido a pequena diferença entre uma e outra.

Segundo definição de lasbeck (2002, p.84), metáfora "é o nome dado ao emprego de um termo ou expressão num sentido diferente do seu significado historicamente mais comum, "literal" ou "próprio"”."

Muitos slogans utilizam a metáfora na sua construção, para entendimento dessa figura de linguagem é fundamental entender que ela utiliza o deslocamento de sentido por similares. $\mathrm{Na}$ semiótica, a metáfora se configura como um novo signo resultante da conjunção de outros signos colocados na contiguidade. A criação desse signo não tem um objeto (referente) específico; seu objeto e um outro signo, sendo assim a metáfora é um metassigno. (PEREZ, 2004)

Em vista dos argumentos apresentados, entende-se então que a metáfora estabelece relações de comparação entre dois elementos semelhantes. Enquanto a metonímia, é uma figura de linguagem formada a partir de relações de vizinhança, adjacência ou aproximação entre dois elementos, e não a partir de relações de semelhanças como a metáfora. (NEGRI, 2011).

Negri (2011, p. 130), ressalta ainda que uma "metonímia pode ser formada igualmente, quando se toma uma parte para significar todo um sistema, preservando-se o contexto em que está alocado".

Para Bertomeu (2006) e metonímia consiste em utilizar uma palavra por outra, com a qual se acha relacionada e essa troca não se faz por semelhança entre elas, mas porque uma evoca a outra.

Para lasbeck, nas relações metonímicas o objeto ou ideia são percebidos através de alguns de seus componentes ou por uma variante dele que melhor o caracterize nas intenções de comunicação.

\section{SLOGANS DA COCA-COLA}
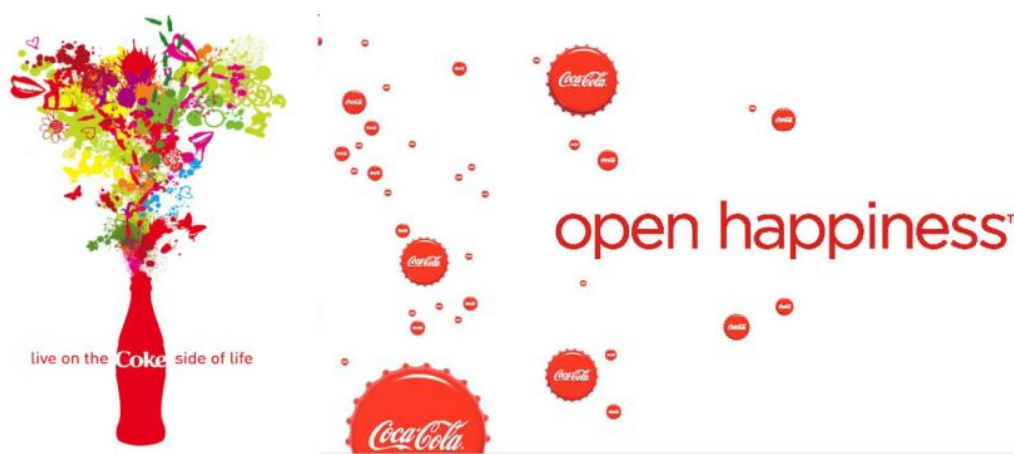

Figura 01. Slogans da Coca-Cola

Fonte: Google

A fim de confirmar a hipótese de que existe uma relação entre os slogans, o posicionamento da marca e os valores que

a mesma quer passar ao seu público-alvo, foi realizado uma pesquisa documental, tendo como objeto de estudos slogans da Coca-Cola.

De 1886 a 2016, a Coca-Cola trabalhou 46 slogans, para facilitar o estudo do presente trabalho, foi selecionado para análise apenas dois slogans. O critério para seleção dos slogans foi pelo fato de serem os últimos a serem trabalhos para a marca e estarem mais alinhados aos atuais valores da empresa. 
Os slogans selecionados para análise são: The Coke Side of Life - Viva o Lado Coca-Cola da Vida" (2006) e Open Happiness - Abra a felicidade. (2009).

Para compreender como é possível essa relação foi analisado e listados todos os princípios e valores da marca e relacioná-los com os slogans escolhidos.

Ao analisar os slogans Viva o Lado Coca-Cola da Vida e Abra a Felicidade, percebe-se facilmente que há a utilização da figura de linguagem metonímia em ambos. No primeiro a relação metonímica está na utilização do nome da marca Coca-Cola utilizada como substituto de outras palavras de sentido positivo que representaria o lado Coca-Cola da vida. Apesar de nos dias atuais os consumidores estarem cientes dos males causados pelo consumo do refrigerante, a marca deixa claro em sua comunicação, como pode ser verificado na Figura 1, que o lado Coca-Cola da vida, é o melhor lado, o lado mais divertido e feliz. Fica claro esse posicionamento ao analisar os elementos que estão saindo da garrafa, que são representações signícas de bons momentos, como: bocas, representando felicidade, borboletas representando liberdade, corações simbolizando o amor, esportistas representando a saúde, além de pequenas silhuetas de garrafas de Coca-Cola.

Ao analisar o segundo slogan percebe que a relação metonímica se estabelece de forma inversa ao anterior, nesse caso a palavra Felicidade estaria representando a palavra Coca-Cola. Ao dizer ao consumidor "Abra a Felicidade", a marca insinua que a felicidade está em uma garrafa de Coca-Cola, conforme pode ser percebido na figura 2, em que o slogan está saindo de dentro de uma garrafa aberta com diversas tampinhas voando, ou seja a felicidade foi aberta.

Os dois slogans deixam claro que a Coca-Cola não quer se posicionar como o melhor refrigerante ou refrigerante mais vendido do mundo e sim como algo que promove a felicidade ou que está presente nos momentos mais felizes da vida. Apesar dos danos à saúde causado pelo consumo excessivo do refrigerante, a marca de fato está presente todos os momentos felizes na vida dos seus consumidores e a marca soube fazer bom uso disso ao criar seu posicionamento, ela deixa isso claro em sua missão, que é entre outros, é refrescar o mundo em corpo, mente e espírito, ou seja, ela não quer apenas matar a sede de quem a consome, ela quer ser uma promotora da felicidade e de bons momentos.

\section{CONSIDERAÇÕES FINAIS}

O slogan faz parte do discurso da empresa e é entendido como sua identidade, constituindo um dos fortes elementos que contribui para a formação da imagem da empresa junto ao público-alvo. Por isso, deve estar alinhado aos objetivos e ao valor que produto/empresa pretende entregar. (PEREZ, 2004)

Ao analisar os princípios e valores da Coca-Cola e dois de seus slogans, ficou claro que há uma relação entre os valores que a marca deseja passar aos seus consumidores. Mesmo sem conhecer esses princípios, muitos consumidores poderiam dizer que o posicionamento da marca seria o de proporcionar bons momentos, devido ao fato de a marca comunicar isso a eles inconscientemente através de suas campanhas e slogans.

\section{REFERÊNCIAS}

BERTOMEU, João Vicente Cegato. Criação na redação publicitária. São Paulo: do Autor, 2006. 133 p.

COCA-COLA (Brasil). Empresa. História da Marca. 2016. Disponível em: <https://www.cocacolabrasil.com.br/coca-cola-brasil/historia-da-marca/>. Acesso em: 30 abr. 2016. 
IASBECK, Luiz Carlos. A Arte dos Slogans: As técnicas de construção das frases de efeito do texto publicitário. São Paulo: Annablume, 2002. 197 p.

KOTLER, Philip; ARMSTRONG, Gary. Princípios de Marketing. São Paulo: Pearson, 2007.

NEGRI, Marina. Contribuições da Língua Portuguesa para a Redação Publicitária. São Paulo: Cengage Learning, 2011. $163 \mathrm{p}$.

PEREZ, Clotilde. Signos da Marca: Expressividade e Sensorialidade. São Paulo: Pioneira Thomson Learning, 2004. $174 \mathrm{p}$.

RIES, Al; TROUT, Jack. Posicionamento: A batalha pela sua mente. 4. ed. São Paulo: Pioneira, 1993. 171 p. (IV). 